\title{
Cystic lesions of the lung in children: classification and controversies
}

\author{
J.T. Stocker*, A.N. Husain ${ }^{\#}$ \\ *Dept of Pathology, Uniformed Services University of the Health Sciences, Bethesda, MD, and ${ }^{\#}$ Dept of \\ Pathology, University of Chicago, Chicago, IL, USA.
}

Correspondence: J.T. Stocker, Dept of Pathology, Uniformed Services University of the Health Sciences, 4301 Jones Bridge Road, Bethesda, MD 20814-4799, USA. Fax: 1 3012951640; E-mail: jstocker @usuhs.mil

Cystic diseases of the lung cover a broad spectrum of lesions, ranging from clearly congenital lesions to lesions acquired through a variety of aetiologies (infection, barotrauma, neoplasia, infarction, etc.; table 1). Although not truly cystic or even pulmonary, a number of both congenital and acquired diseases may be confused both clinically and radiographically with the morphological cystic diseases of the lung. (table 2). A selected few are discussed briefly later in the present chapter.

The organisation and classification of congenital cystic lung diseases began in the mid 1990s with the report by CH'IN and TANG [1] describing a malformation of the lung in an infant born to a mother with polyhydramnios. The solid-appearing lung lesion was composed of gland-like alveoli, all lined with cuboidal epithelium. They called the abnormality congenital adenomatoid malformation. Over the following 30 yrs, various authors described other malformations of the lobes of the lung, some of which resembled the lesion described by CH'IN and TANG [1] and others of which were cystic and composed of bronchioles and other acinar structures in various combinations. This collection of lesions became known as congenital cystic adenomatoid malformation (CCAM).

Table 1. - Cystic lesions

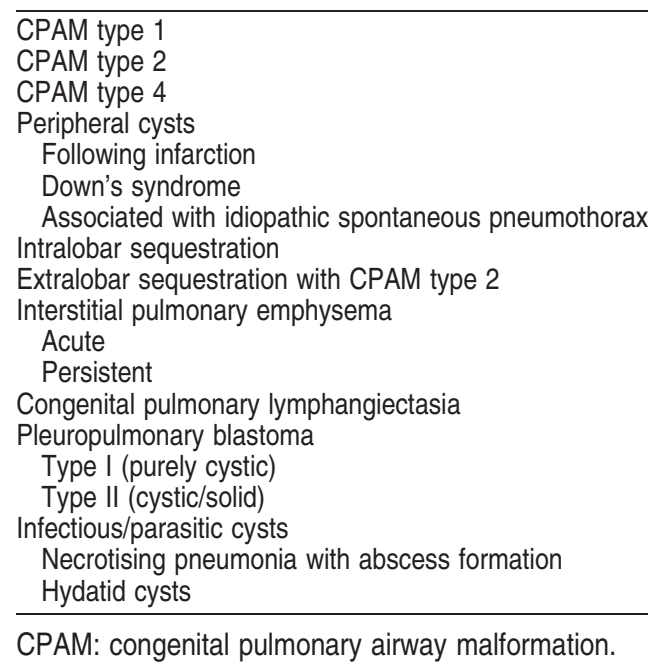

Eur Respir Mon, 2007, 39, 1-20. Printed in UK - all rights reserved. Copyright ERS Journals Ltd 2007; European Respiratory Monograph; ISSN 1025-448x.

Purchased by,

From: European Respiratory Society Publications (reader.ersjournals.com) 
Table 2. - Pseudocystic or pseudopulmonary lesions

\begin{tabular}{l}
\hline CPAM type 0 \\
CPAM type 3 \\
Infantile lobar emphysema \\
Congenital diaphragmatic hernia \\
Long-standing "healed" bronchopulmonary dysplasia \\
Bronchogenic cyst \\
Pneumothorax \\
Pneumomediastinum \\
Pneumopericardium \\
Respiratory syncytial virus pneumonia (with air-trapping) \\
Bronchiectasis, as with cystic fibrosis \\
Lymphangioma/vascular malformation
\end{tabular}

CPAM: congenital pulmonary airway malformation.

In 1977, STOCKER, et al. [2] described 35 cases of CCAM and divided them into three groups based on clinical and pathological features. Type 1, the most frequently occurring, were lesions that presented in the first hours to days of life and consisted of large cysts composed of walls lined with respiratory epithelium interspersed with tuft-like collections of mucogenic cells. Type 2 were composed of back-to-back bronchiolar-like structures and were associated with other anomalies, which are often severe (e.g. bilateral renal agenesis), in almost $50 \%$ of cases. Type 3 were the true adenomatoid lesion of CH'IN and TANG [1] which were often so large as to result in compression and hypoplasia of the other lobes of the lung.

\section{Basis for new and expanded classification of congenital pulmonary airway malformation}

During the period following the publication of the classification of CCAM, $>250$ cases of cystic and noncystic malformations of the lung were reviewed, and it was determined that there were a significant number of cases within this set that were different enough clinically, radiographically and morphologically (tables 3 and 4) to encompass two other groups of lesion, leading to the proposal of a new classification incorporating five types $[3,4]$. In addition, the morphological appearance of the five types suggested differing sites of origin of the lesions within the developing tracheobronchial tree (fig. 1).

The expanded classification also included a new term to replace CCAM. STOCKER [4] suggested renaming this group of malformations congenital pulmonary airway malformation (CPAM), since only one of the types (type 3) is adenomatoid and only three (types 1, 2 and 4) are cystic.

The first lesion in this new classification, called CPAM type 0, is a rarely occurring malformation originally described, by RUTLEDGE and JENSEN [5], as acinar dysplasia. The lesion consists of abnormally formed bronchial structures surrounded by loose vascular mesenchyme. There is little development beyond the bronchial stage and the lesion is incompatible with life.

CPAM type 4, the other new type, consists of multiple large cysts lined only with type 1 and 2 alveolar cells over a wall composed of loose-to-dense mesenchyme containing multiple large-to-small vessels. Children with CPAM type 4 vary in age at presentation from 1 day to 4 yrs, with $25 \%$ presenting in the first week of life, $45 \%$ between 1 week and 6 months, and the remaining 30\% between 15 months and 4 yrs. Most children display various degrees of respiratory distress, including sudden respiratory distress 
Table 3. - Clinical features of congenital pulmonary airway malformation (CPAM)

\begin{tabular}{|c|c|c|c|c|c|}
\hline & Type 0 & Type 1 & Type 2 & Type 3 & Type 4 \\
\hline $\begin{array}{l}\text { In utero } \\
\text { ultrasound }\end{array}$ & Small lungs & $\begin{array}{c}\text { 1st trimester cystic mass } \\
\text { that shrinks in } \\
\text { 2nd-3rd trimester }\end{array}$ & $\begin{array}{l}\text { Normal-to-ill- } \\
\text { defined-mass }\end{array}$ & $\begin{array}{l}\text { Progressively } \\
\text { enlarging } \\
\text { mass }\end{array}$ & $\begin{array}{l}\text { Normal-to-cystic } \\
\text { mass, as with } \\
\text { CPAM type } 1\end{array}$ \\
\hline $\begin{array}{l}\text { Age at } \\
\text { presentation }\end{array}$ & Birth & Birth to adolescence & Birth & In utero to birth & Birth to 4 yrs \\
\hline Symptoms & $\begin{array}{l}\text { Stillbirth; } \\
\text { severe RD }\end{array}$ & $\begin{array}{c}\text { Minimal-to-severe } \\
\text { RD }\end{array}$ & None-to-mild RD & $\begin{array}{c}\text { Stillbirth; severe } \\
\text { RD }\end{array}$ & $\begin{array}{l}\text { None to RD to } \\
\text { pneumothorax }\end{array}$ \\
\hline $\begin{array}{l}\text { Associated } \\
\text { anomalies }\end{array}$ & Rare & Rare & $\begin{array}{l}50 \% \text {, including renal } \\
\text { agenesis }\end{array}$ & $\begin{array}{c}\text { Pulmonary } \\
\text { hypoplasia } \\
\text { of uninvolved } \\
\text { lung }\end{array}$ & Rare \\
\hline Treatment & None & Resect lobe(s) & $\begin{array}{l}\text { Depends on other } \\
\text { abnormalities }\end{array}$ & Resect lobe(s) & Resect lobe(s) \\
\hline Outcome & $\begin{array}{l}\text { Incompatible } \\
\text { with life }\end{array}$ & $\begin{array}{l}\text { Excellent following } \\
\text { surgery }\end{array}$ & $\begin{array}{l}\text { Depends on severity } \\
\text { of other abnormalities }\end{array}$ & $\begin{array}{c}\text { Poor: depends } \\
\text { on severity of } \\
\text { pulmonary } \\
\text { hypoplasia }\end{array}$ & $\begin{array}{c}\text { Excellent } \\
\text { following } \\
\text { surgery }\end{array}$ \\
\hline
\end{tabular}

RD: respiratory distress.

accompanying a tension pneumothorax in $\sim 15 \%$ of cases. CPAM type 4 in older children may be asymptomatic and discovered incidentally on routine examination. There is an almost equal male to female ratio and no racial predilection. Other anomalies are rarely seen. Two brothers, one aged 6 weeks and the other 17 months, both exhibited CPAM type 4 lesions.

The CPAM type 4 lesion can be found in any lobe (right lung more than left lung) and may involve more than one lobe in $\sim 20 \%$ of cases. Bilateral involvement has been seen in a 6-month-old male and a 3-yr-old female. Resection is usually curative, even with bilateral involvement. The lesions vary greatly in size, with mortality related to very large lesions in young infants. In two infants who died on the first day of life (the only deaths among 23 cases), the involved lobes equalled or exceeded the expected weight of the entire lung. Cysts also vary greatly in size, with some cysts exceeding $10 \mathrm{~cm}$ in diameter in older children. [3]

The differential diagnosis of CPAM type 4 includes the other forms of CPAM (whose features are summarised below) and the purely cystic form of pleuropulmonary blastoma (PPB), which may also be seen in young infants [6]. Cystic PPB is characterised by multiple large cysts lined with cuboidal-to-ciliated columnar epithelium overlying a wall that, in areas, displays a well-formed cambium layer associated with the embryonal rhabdomyosarcoma component of PPB. Significant discussion has taken place in the literature in the past $8-10$ yrs as regards the relationship of CPAM type 4 to cystic PPB (see below).

\section{Clinical and morphological features of the five types of CPAM}

\section{CPAM type 0}

CPAM type 0 was originally termed acinar dysgenesis (agenesis) by RUTLEDGE and JENSEN [5], and appears to correlate with failure of development of the lung beyond the tracheobronchial origin (fig. 1). CPAM type 0 is the least frequently occurring of the CPAM lesions, with fewer than 12 cases described in the literature [7, 8].

Clinically, infants present with cyanosis and severe respiratory distress at birth and survive only a few hours unless treated with extracorporeal membrane oxygenation, but 
J.T. STOCKER, A.N. HUSAIN

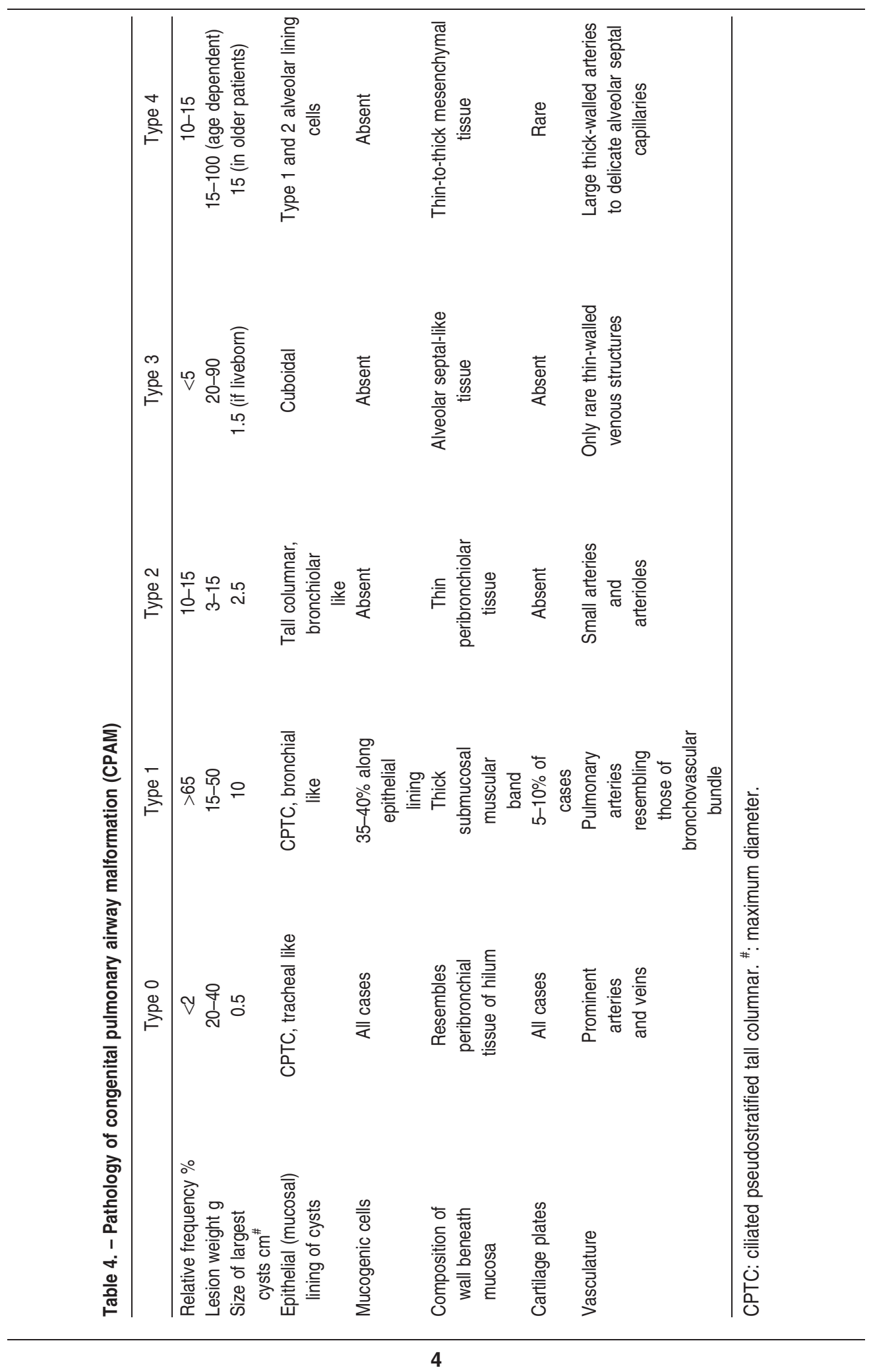

Purchased by ,

From: European Respiratory Society Publications (reader.ersjournals.com) 


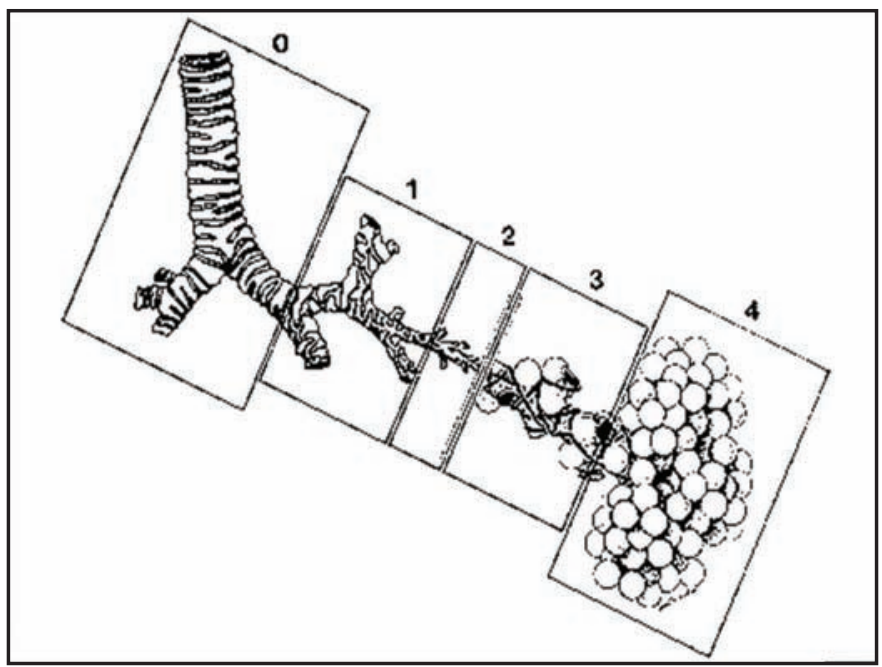

Fig. 1. - Schematic drawing of tracheobronchial tree illustrating the possible site of origin of the five types $(0-4)$ of congenital pulmonary airway malformation based on the histological features of each type.

are then unable to survive after removal of that support. In the few cases reported, an association with cardiovascular abnormalities and dermal hypoplasia has been noted.

Grossly, the lungs are small, with a total weight of $<50 \%$ of that expected based on gestational age. The lungs are firm and show a diffusely granular surface (fig. 2). Microscopically, the tissue consists entirely of bronchial-like structures with muscle, glands and numerous cartilage plates. More distal components, such as proximal bronchioles, are only rarely seen. The intervening tissue is prominent and consists of loose-to-dense mesenchymal cells and collagen, along with thick-walled arteries, large thin-walled vascular channels, collections of amorphic basophilic debris and foci of extramedullary haematopoiesis.

\section{CPAM type 1}

CPAM type 1 is composed of medium and large cysts that appear to be primarily of bronchial and bronchiolar origin. It is the most frequently occurring type $(60-70 \%$ of cases), and, although seen primarily in the first month of life, may also be first diagnosed in older children and, rarely, young adults [4].

Clinically, most patients present with increasing respiratory distress shortly after birth, but older patients may present with cough, fever or chest pain. The severity of symptoms in newborn children is related to the size of the lesion as a whole and to the size and expansion of individual cysts. The lesion may present in utero as a solid thoracic mass during the first trimester, but, in most instances, will collapse during the second or third trimester to allow normal growth of the uninvolved lobes of the lung. The lesion then re-expands after birth as the cysts fill with air. Radiographically, air-filled or air/fluidfilled cysts are apparent in one or more lobes, with compression of adjacent lung, flattening of the diaphragm and shift of the mediastinum.

Grossly, cysts are usually limited to one lobe $(95 \%)$, but are rarely multiple or bilateral (fig. 3). The present authors have seen one case in which all lobes were affected. The cysts 

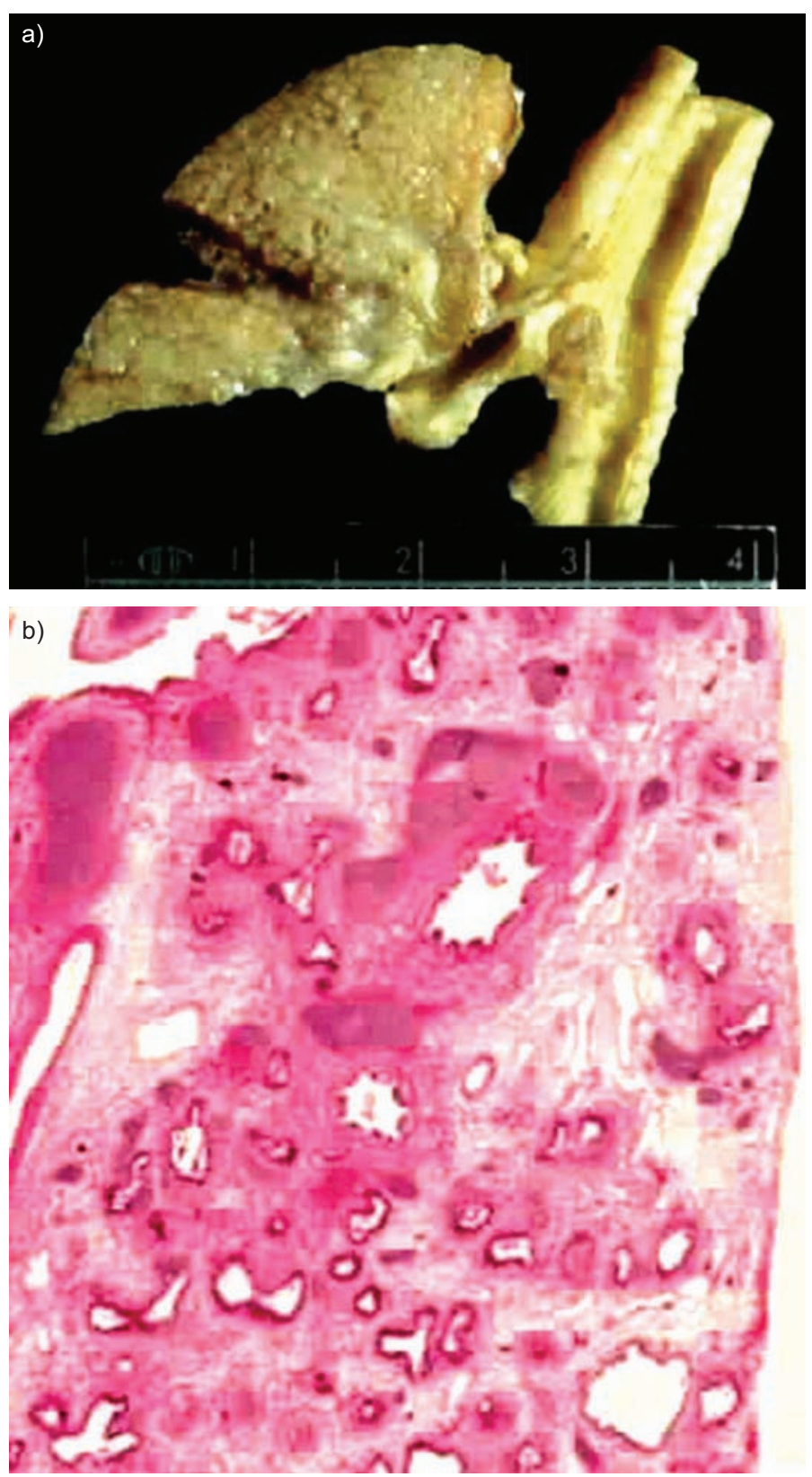

Fig. 2. - Congenital pulmonary airway malformation type 0. a) Grossly, the lung is firm with a finely nodular surface, reflecting the presence of bronchial structures throughout the lesion. b) The lesion is composed of bronchovascular islands surrounded by loose fibrovascular connective tissue (haematoxylin and eosin stain).

range $1-10 \mathrm{~cm}$ in size, are thin-walled when distended and lined with a smooth membrane with vascular structures visible beneath the surface.

Microscopically, the cysts are lined with ciliated pseudostratified columnar epithelium in polypoid folds with interspersed segments of mucogenic cells in $\sim 35 \%$ of cases (fig. 4 ). 

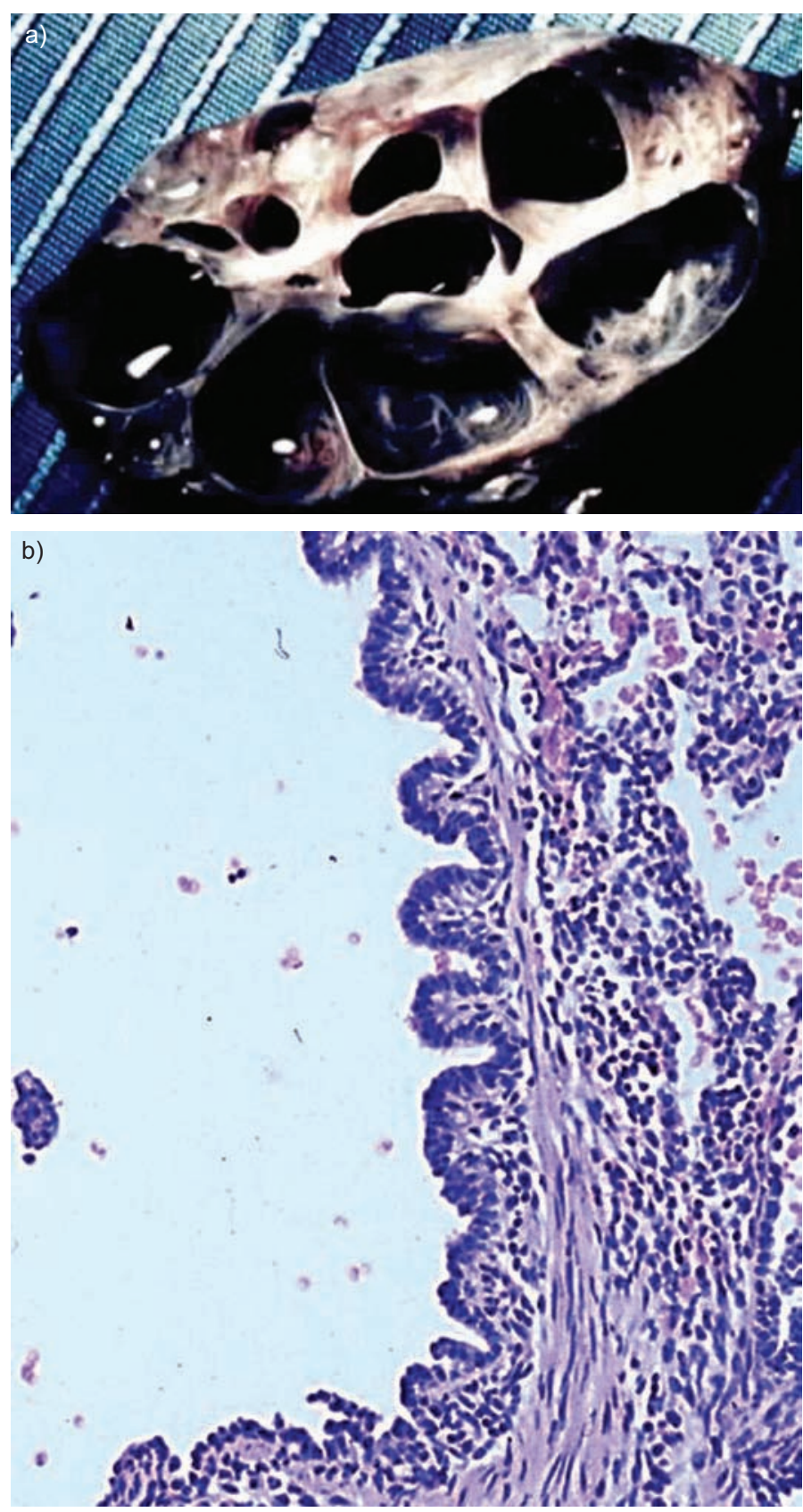

Fig. 3. - Congenital pulmonary airway malformation type 1. a) Grossly, the lesion is composed of multiple interconnecting cysts. b) The cysts are lined with respiratory epithelium (ciliated pseudostratified tall columnar epithelium) overlying a wall composed of bands of smooth muscle and vascular connective tissue (haematoxylin and eosin stain).

The cyst walls are composed of fibromuscular tissue and occasional cartilage islands. Adjacent parenchyma contains smaller cysts resembling bronchioles. In the presence of chronic inflammation (lymphoid aggregates, fibrosis, macrophages, etc.), the diagnosis of 

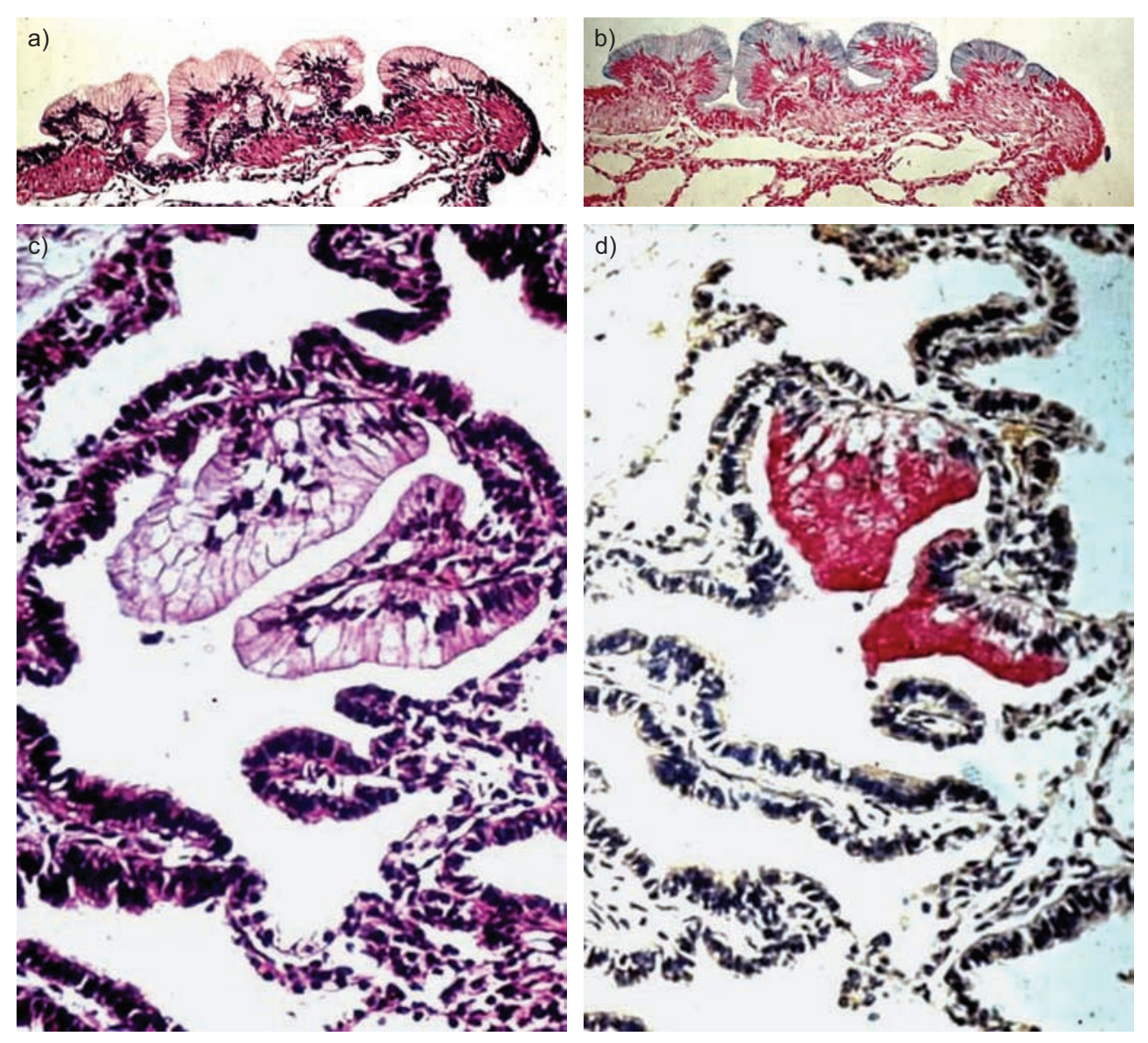

Fig. 4. - Congenital pulmonary airway malformation type 1. In $\sim 35-40 \%$ of cases, clusters of mucogenic cells: a, b) lie along the surface of the cysts; or c, d) fill small alveolar duct-like structures. a, c) haematoxylin and eosin stain; b) alcian blue; and d) mucicarmine.

CPAM cannot be made because of the normal response of the lung to inflammation and abscesses, i.e. repair by fibrosis and epithelisation of healed abscesses with columnar-topseudostratified columnar epithelium.

CPAM type 1 is amenable to surgical resection with good long-term survival (in the absence of a rarely occurring severe associated anomaly).

\section{CPAM type 2}

CPAM type 2 is composed of cysts $0.5-2.0 \mathrm{~cm}$ in diameter that resemble bronchioles.

The clinical picture is often dictated by the occurrence, in $\sim 50 \%$ of cases, of other severe anomalies (sirenomelia, renal agenesis/dysgenesis, diaphragmatic hernia and cardiovascular). When an isolated lesion, it may be seen in the first month of life as mildto-severe respiratory distress. Radiographically, the lesion may be difficult to visualise as most lesions exhibit cysts of only $0.5-1.0 \mathrm{~cm}$ in diameter.

Grossly, the lesions are smaller than other CPAM lesions and blend with the adjacent 

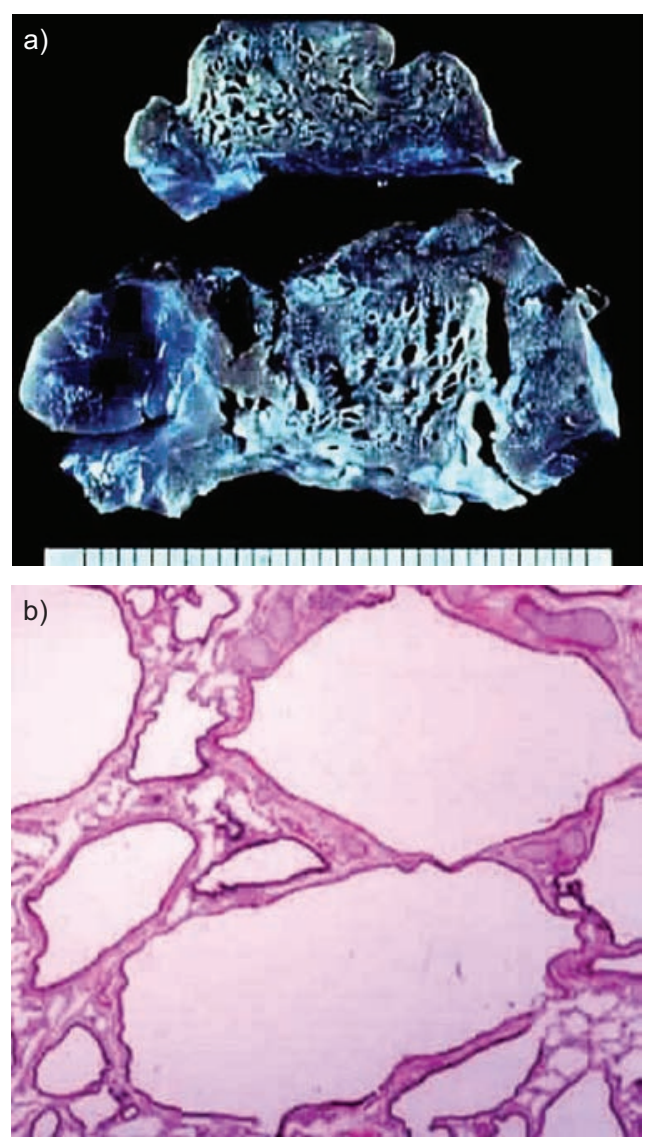

Fig. 5. - Congenital pulmonary airway malformation type 2. a) Small cysts $(0.5-1.5 \mathrm{~cm})$ blend with normal parenchyma. b) Microscopically, these cysts consist of back-to-back bronchiolar-like structures lined with simple columnar-to-cuboidal epithelial cells (haematoxylin and eosin stain).

normal parenchyma (fig. 5). They are composed of multiple small cysts $(0.5-1.0 \mathrm{~cm}$ diameter) lined with a smooth membrane $[3,9]$.

Microscopically, the lesion is composed of back-to-back dilated bronchioles separated by irregular alveolar duct-like structures. Small arteries, arterioles and venules are interspersed among the bronchioles. CPAM type 2 may be seen in 50\% of extralobar sequestrations [10].

Surgical resection in isolated lesions, including those associated with extralobar sequestration, is frequently successful. In cases with other severe anomalies, survival is dependent upon the severity of the anomalies and the ability to successfully treat them.

\section{CPAM type 3}

CPAM type 3, the original congenital adenomatoid malformation described in 1949 by CH'IN and TANG [1], is composed of gland-like structures resembling terminal/respiratory bronchioles and alveolar ducts.

Clinically, the lesion occurs almost exclusively in males, is associated with maternal polyhydramnios in nearly $80 \%$ of cases and may lead to death in utero. Live-born infants 

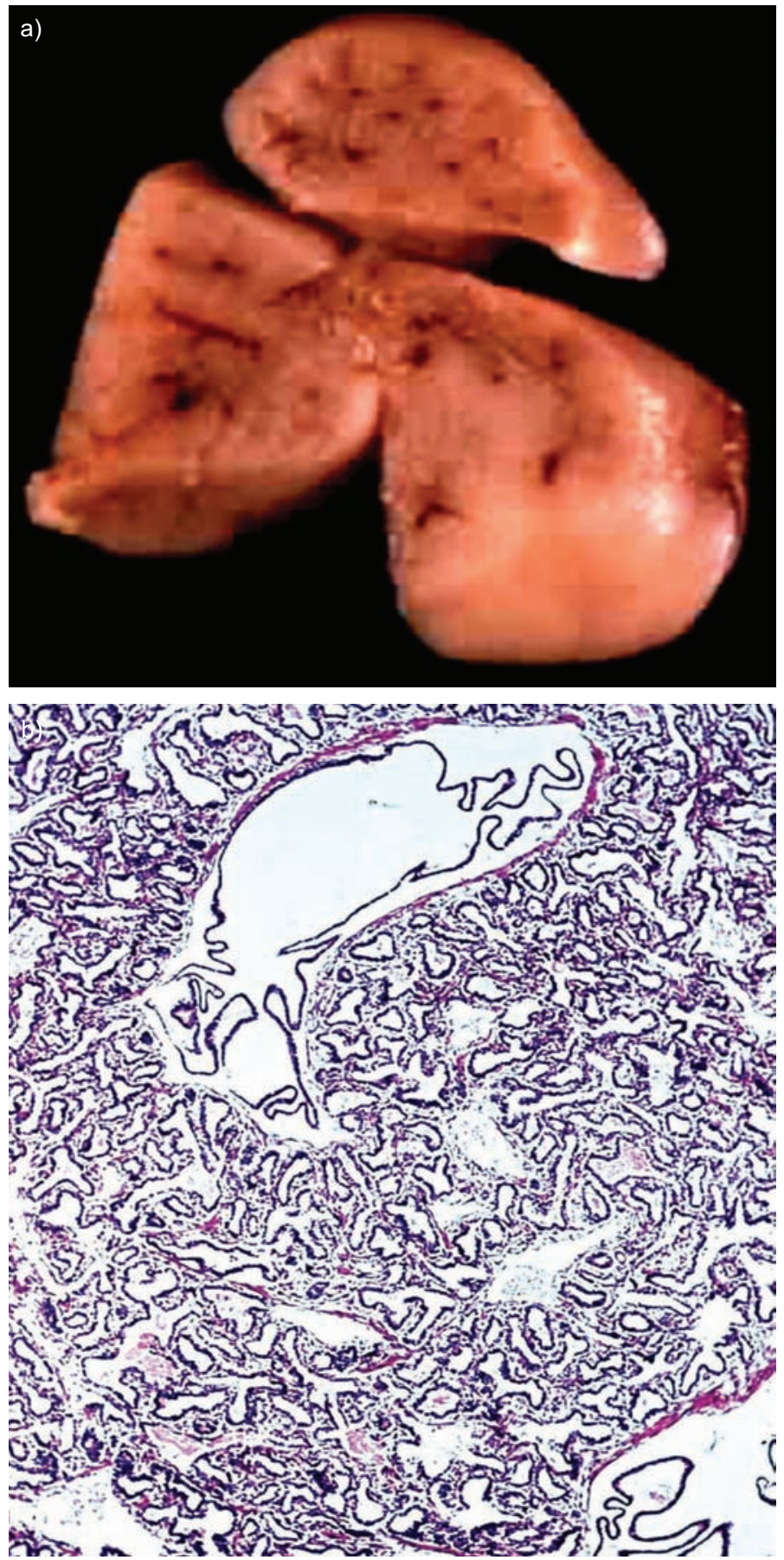

Fig. 6. - Congenital pulmonary airway malformation type 3. a) The lesion is a solid mass resembling atelectatic parenchyma. Only rarely are small "cysts" seen, probably representing dilated bronchioles. b) The lesion consists entirely of small bronchiole- and alveolar duct-like structures lined with cuboidal epithelium. Note the virtual absence of arterial structures (haematoxylin and eosin stain). 
show early severe respiratory distress due to associated pulmonary hypoplasia of the uninvolved lung.

Grossly, the lesion is large, somewhat firm and bulky, and involves an entire lobe or even an entire lung, producing mediastinal shift and compression of the adjacent lung, accounting for its hypoplasia (fig. 6). However, if aerated, the lesion may display randomly scattered thin-walled cysts of $0.5-1.5 \mathrm{~cm}$ in diameter.

Microscopically, the entire lesion is composed of randomly scattered bronchiolar/ alveolar duct-like structures lined with low cuboidal epithelium and surrounded by alveoli, also lined with cuboidal epithelium. Arteries and even arterioles are notably absent from the lesion.

Survival is possible with resection of the lobe or lung if hypoplasia of the remaining lung is mild enough (i.e. $\geq 30-40 \%$ of the expected weight remains) to permit adequate oxygenation.

\section{CPAM type 4}

CPAM type 4 is composed of large cysts with no readily discernible lining and thus resembles distal acinar structures, i.e. alveolar saccules/alveoli.

Clinically, the lesion may be seen in infants or young children (age range birth to $4 \mathrm{yrs}$ ), and they may present with mild respiratory distress, sudden respiratory distress due to tension pneumothorax, pneumonia or, on occasion, an incidental finding with no symptoms. Radiographically, the large air-filled cysts are readily identified, along with mediastinal shift and an occasional pneumothorax [4].

Grossly, large thin-walled cysts, often $8-10 \mathrm{~cm}$ in diameter in older infants and young children, are present at the periphery of the lobe (fig. 7). Their internal surface appears to be a smooth membrane, and vessels can often be seen beneath the surface. In newborns, the cysts are much smaller $(0.3-2.0 \mathrm{~cm})$.

Microscopically, both small and large cysts are lined with flattened epithelial cells (type 2 alveolar lining cells) over most of the wall, with only rare areas in which low cuboidal epithelium may be present. The character of the lining cells can be determined with the use of surfactant and other immunohistochemical stains associated with alveolar lining cells (fig. 8). A capillary bed of varying density is present beneath the epithelial lining and may have a few lymphocytes and macrophages scattered throughout it.

The walls of the larger cysts may be $0.1-0.3 \mathrm{~cm}$ thick and are composed of loose mesenchymal tissue containing prominent arteries and arterioles. These large arteries may display a multilayered muscular media far thicker than that seen in normal peripheral acinar vessels (fig. 9). Dense connective tissue may be present in older patients in some cases.

The loose mesenchyme must not be confused with similar tissue seen in the cystic type of PPB (see below), in which mononuclear cells (rhabdomyoblasts) may be present in areas beneath strips of cuboidal/columnar epithelium. For this reason, multiple sections of cyst walls should be taken when examining a suspected case of CPAM type 4 in order to exclude the diagnosis of purely cystic PPB. With resection of the involved lobe, the survival of children with CPAM type 4 is excellent.

\section{CPAM type 1 and bronchioloalveolar carcinoma}

Bronchioloalveolar carcinoma (adenocarcinoma; BAC) is the most common form of bronchogenic carcinoma in children (fig. 10), although the lesion as a whole is most frequently seen in the elderly [11, 12], and may rarely be familial [13]. It occurs with cough, pneumonia and chest pain, but, if peripheral, may be asymptomatic. Initial 


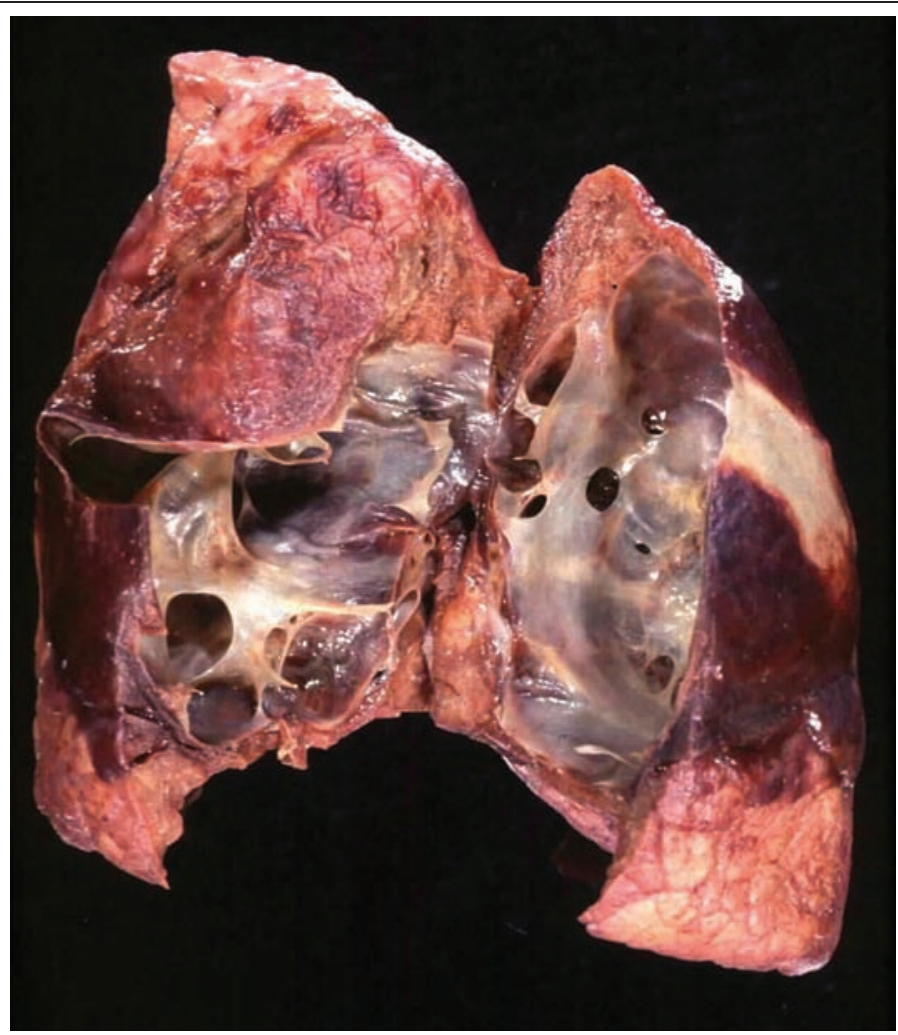

Fig. 7. - Congenital pulmonary airway malformation type 4. Cut section of the lung displaying multiple large cysts with thin walls traversed by areas of density representing vessels in the walls.

symptoms may be related to disseminated disease, such as bone pain or weight. As a subtype of adenocarcinoma, BAC exhibits an excellent prognosis when $<2 \mathrm{~cm}$ in diameter at the time of diagnosis. Indeed, there is almost $100 \% 5$-yr survival under these circumstances [14].

\section{Does CPAM type 1 with mucinous foci predispose to $\mathrm{BAC}$ ?}

In recent years, the question of the association of CPAM type 1 with BAC has been raised on the basis of case reports of BAC having occurred in older children who, as infants, had had CPAM type 1 partially or completely resected. The first such report, in 1991, was that of BENJAMIN and CAHILL [15], followed in 1995 by that of RiBET et al. [16]. In 1998, ОтА et al. [17], having previously noted gastric mucins in mucinous BAC, studied 12 out of 26 cases of CPAM type 1 containing mucous cells and found mucins similar to those of the mucinous BACs. This association has been supported by the finding of similar genetic abnormalities (including gains in chromosomes 2 and 4 ) in both CPAM type 1 goblet cells and the cells of BAC [18]. Most recently, IoACHIMESCU and Menta [14] described the 15-yr course of the development of a BAC (diagnosis at age 6 yrs, along with CPAM type 1), which subsequently developed into an invasive adenocarcinoma. They emphasised the unique feature of a lesion that may exhibit lack of growth for years before becoming an aggressive lesion and suggest the interim phase of atypical adenomatous hyperplasia between the CPAM-1 and BAC before it becomes an invasive adenocarcinoma. 

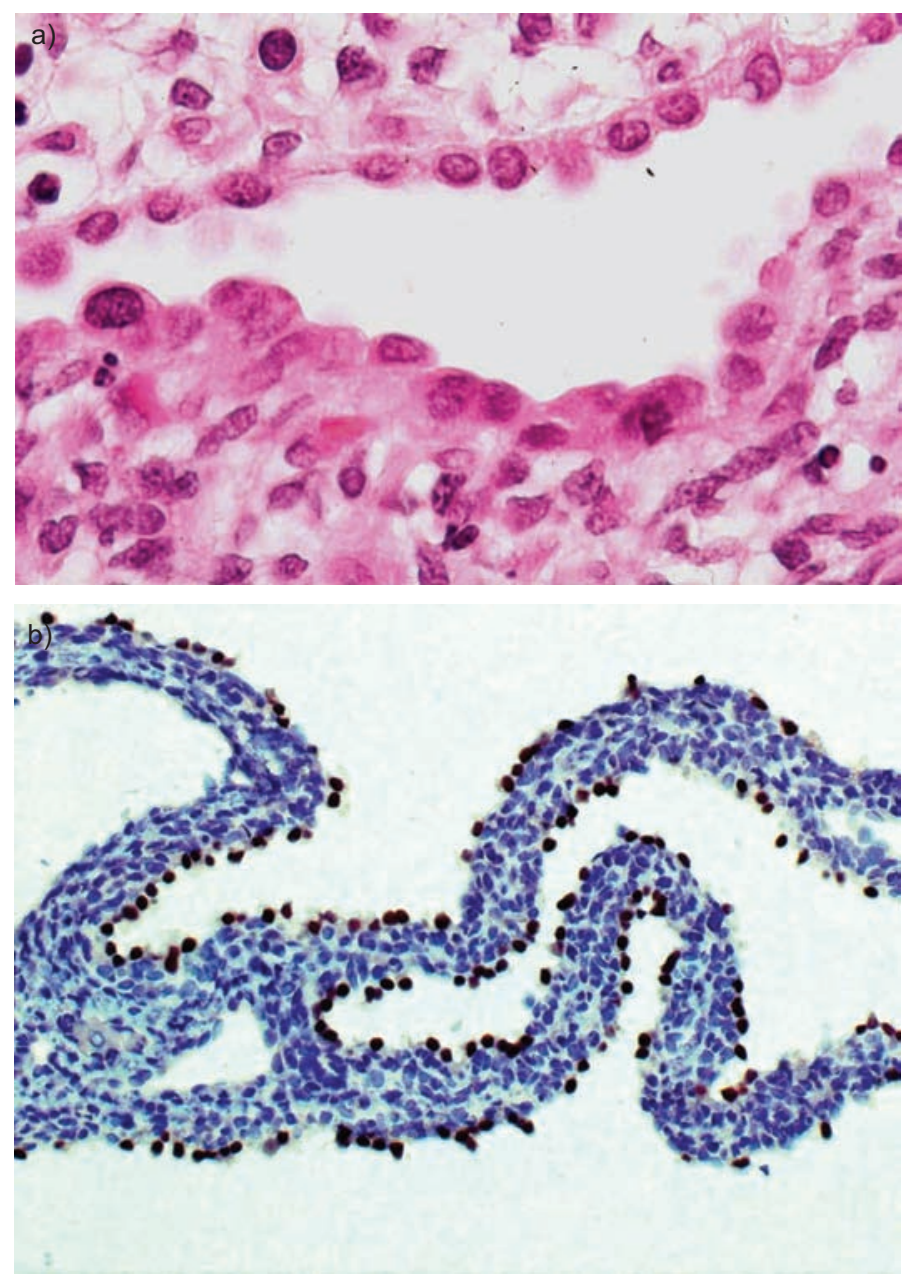

Fig. 8. - Congenital pulmonary airway malformation type 4. a) The cysts are lined with cells with round nuclei and scant cytoplasm (haematoxylin and eosin stain). b) These lining cells are marked intensely with thyroid transcription factor (TTF), indicating that they are alveolar lining type 2 cells (TTF immunohistochemical stain).

\section{CPAM type 4 and PPB}

PPB is a rare primary pulmonary tumour in children, with $\sim 75$ cases reported in the literature [19]. There is an equal sexual incidence and the vast majority occur during the first 4 yrs of life, although cases have been seen in older children and in an adult aged 36 yrs. Presenting symptoms include respiratory distress, nonproductive cough, fever, chest pain or a combination of symptoms of days' to weeks' duration [6].

Conditions associated with PPB are seen in nearly $25 \%$ of patients, and include a positive family history of childhood neoplasms, including PPBs, in siblings, cousins and other close relatives. Other associations in PPB patients include medulloblastoma, ovarian teratoma, Hodgkin's lymphoma, leukaemia, thyroid dysplasia and neoplasia, malignant germ cell tumour and nephroblastic lesions.

Imaging studies may show a solid $(62 \%)$ or cystic $(38 \%)$ lesion that may be 


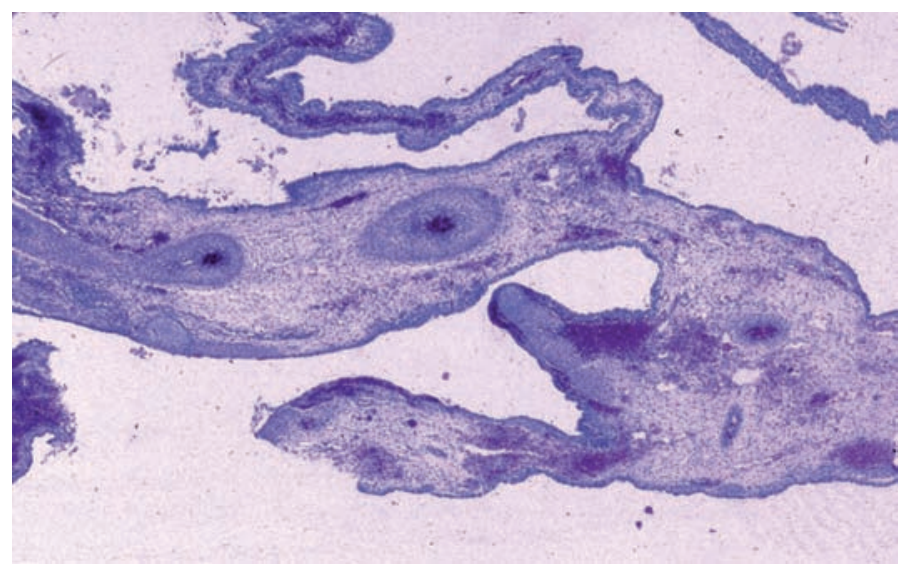

Fig. 9. - Congenital pulmonary airway malformation type 4. Cross-section of the cyst walls displaying thick mesenchymal tissue containing thick muscularised arteries (haematoxylin and eosin stain).

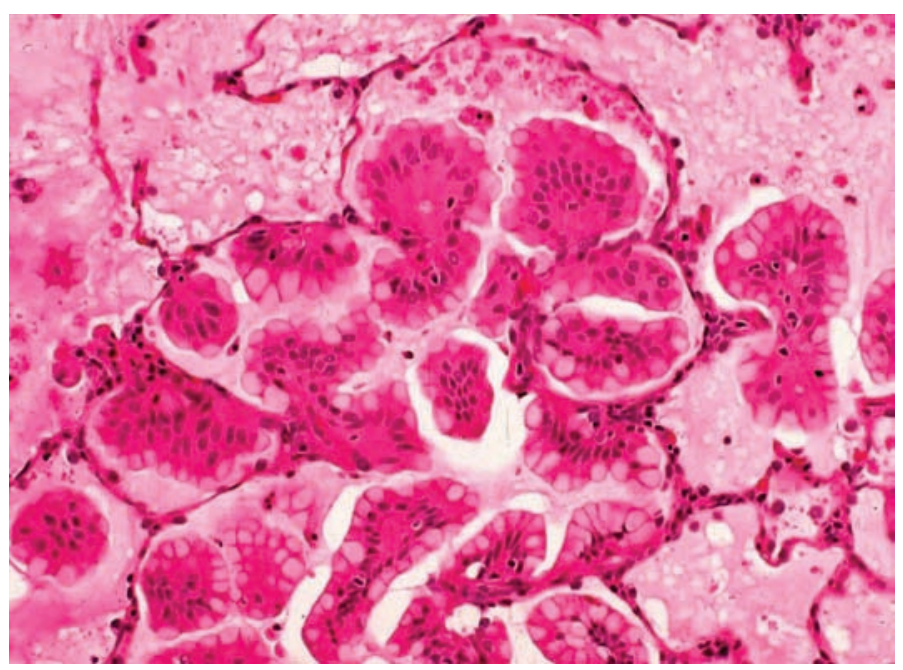

Fig. 10. - Bronchioloalveolar carcinoma. Alveoli are filled with mucin and polypoid clusters of mucogenic cells. The nuclei of the cells retain their basal orientation. Note the absence of any apparent invasion (haematoxylin and eosin stain).

mediastinally or pleurally based, as well as intrapulmonary. Tumours are classified as type I (cystic; $14 \%$ of cases), type II (cystic and solid; $48 \%$ of cases) and type III (solid; $38 \%$ of cases).

The multilobated masses measure $8-23 \mathrm{~cm}$ in diameter and weigh up to $1,100 \mathrm{~g}$. Microscopically, the cystic areas are composed of small-to-large cysts lined with respiratory-type epithelium overlying a loose-to-dense fibrous stroma that, in areas, is composed of primitive small cells in a cambium-like arrangement beneath the epithelium (fig. 11). The solid areas of types II and III PPB consist of blastematous islands of loose mesenchyme blending into fibrosarcoma-like foci, nodules of benign appearing to overtly 


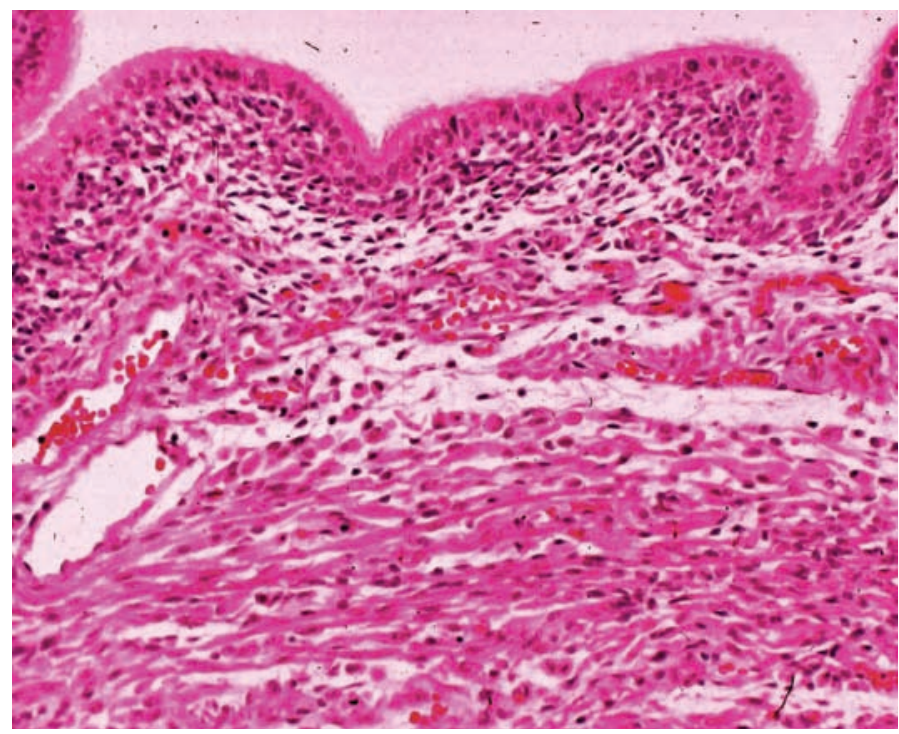

Fig. 11. - Pleuropulmonary blastoma. Ciliated columnar epithelium overlies a dense layer of small round blue cells (rhabdomyoblasts on immunohistochemical staining), which, in deeper layers, become fewer in number and mixed with oval and strap-like cells and, eventually, densely eosinophilic skeletal muscle-like cells (haematoxylin and eosin stain).

malignant cartilage, rhabdomyoblasts and areas of large bizarre pleomorphic multinucleate mesenchymal cells.

Immunohistochemical staining is variable from one tissue type to another. Trisomy 2 and 8 have been noted in cytogenetic studies of the tumours. Most recently, RoQuE et al. [20] reported the comparative genomic hybridisation of PPB and found several chromosomal imbalances (e.g. 1q12-q23), whole chromosome gains of 2 and 7, and loss of genetic material at regions 6q130qter, 10pter-p13, 10q22-qter and 20p13.

Local recurrence may develop in $<15 \%$ of type I PPBs, but in $>45 \%$ of type II and III PPBs. Metastatic disease occurs in 25\% of patients (all with type II or III PPB), chiefly to the brain/spinal cord or bone. Patients with pleural or mediastinal involvement fare significantly worse than those without such involvement. In a series of 50 cases reported by PRIEST et al. [6], 5-yr survival was $83 \%$ for type I and $42 \%$ for types II and III.

\section{Can purely cystic pleuropulmonary blastoma arise in a pre-existing CPAM type 4?}

Although superficially resembling CPAM type 1 or 4, purely cystic PPB lesions are, in the experience of the present authors and others [21], distinctly different morphologically in that the CPAM type 1 lesion (lined with respiratory epithelium) does not have a loose mesenchymal component in its wall, and the CPAM type 4 lesion (with a loose-to-dense mesenchymal wall) is lined with thinned type 2 alveolar lining cells, not with cuboidal or columnar cells. Small patches of cuboidal and/or columnar epithelium may occasionally be noted along the wall of CPAM type 4 cysts, but these are usually associated with an adjacent component of a normal bronchiolar structure apparently entrapped in the developing lesion. Nevertheless, in the case of CPAM type 1 or 4 , great care must be taken to exclude the diagnosis of purely cystic PPB. When in question, immunohistochemical stains for rhabdomyoblastoma cells may help in distinguishing the malignant 
cells of cystic PPBs from the normal small round blue cells (lymphocytes, etc.) occasionally present in the walls of CPAM type 1 or 4 .

\section{Other cystic and pseudocystic lesions}

Peripheral cysts. Peripheral air-containing cysts of the lung can be seen in neonates, infants, young children and teenagers. They occur in association with Down's syndrome, as a result of pulmonary infarction, or in association with idiopathic spontaneous pneumothorax. Occlusion of the pulmonary artery in infants can result in peripheral infarction of the lung, which, with necrosis and organisation, can produce subpleural cysts of varying sizes [22]. In Down's syndrome, it has been suggested that the cysts are an intrinsic feature of the disease that may result from reduced post-natal production of peripheral small air passages and alveoli. The air-filled cysts are $0.2-1.0 \mathrm{~cm}$ in diameter and located beneath the pleura. They are formed of vascular fibrous connective tissue walls lined with alveolar lining cells [23].

Sequestrations. Sequestrations are classified as intralobar (often occurring in the older child or young adult and associated with repeated infections, the majority are thought to be acquired) and extralobar (most often occurring in neonates and young children and thought to be congenital), and both can have a cystic component [24]. In many of the former, cystic structures are formed by dilated airways containing mucopurulent material (fig. 12), whereas, in the latter, there is a strong association with CPAM type 2 within the lesion $[10,25,26]$.

Congenital pulmonary lymphangiectasia. Congenital pulmonary lymphangiectasia is a rare, usually fatal, disorder involving both lungs and is characterised by distended lymphatics in the bronchovascular bundle, the interlobular septa and the subpleural space. A few cases of unilobar involvement have been described that were radiologically misdiagnosed as infantile (congenital) lobar emphysema [27]. The lymphatics can be identified immunohistochemically using one of the newer markers specific for lymphatic endothelium (D2-40 antibody or lymphatic vessel endothelial hyaluronan receptor 1).

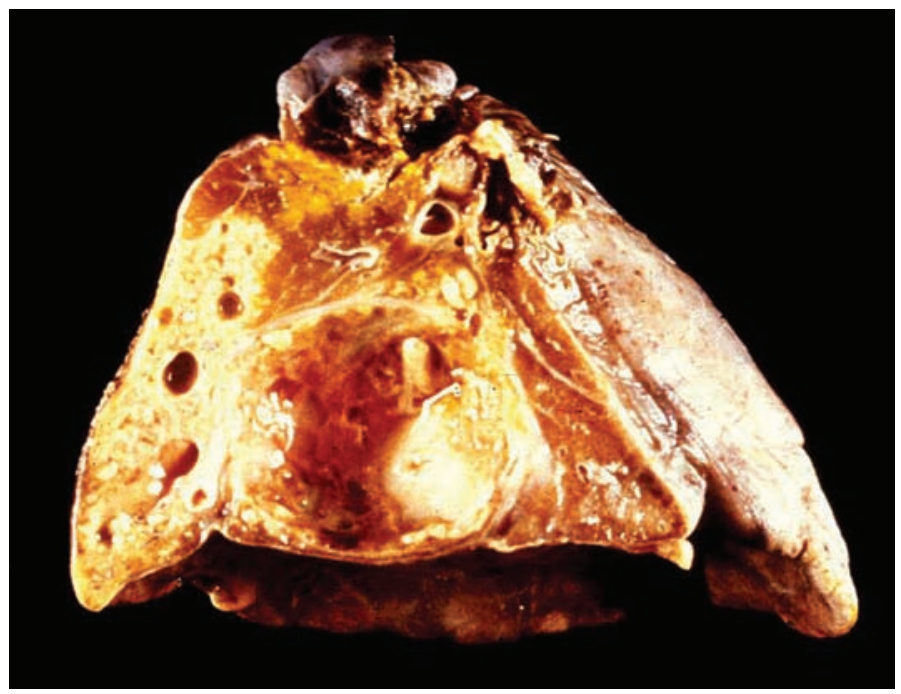

Fig. 12. - Intralobar sequestration. Gross picture of cut surface of resected specimen with a dominant mucusfilled cyst. 
Interstitial pulmonary emphysema. Interstitial pulmonary emphysema is the dissection by air around bronchovascular bundles and along interlobular septa as the result of rupture of alveoli, usually in association with mechanical ventilation. It may also be seen in patients dying due to acute asthma, as a result of cardiopulmonary resuscitation, and in association with a variety of infectious diseases. It may be acute or persistent (characterised by a foreign body giant cell reaction to the air) and may be localised to a single lobe or distributed diffusely through all of the lobes [23, 28]. Some of the air may track into lymphatics (but not the pleural lymphatics), raising the differential diagnosis of congenital pulmonary lymphangiectasia, which also involves the pleural lymphatics. Immunohistochemical staining for endothelial cells is helpful in localising the cysts.

Infantile lobar emphysema. Infantile lobar emphysema refers to an overexpansion of a pulmonary lobe occurring in an infant, leading to pulmonary compromise. Pathologically, there is a spectrum of morphological changes, with the two most common patterns being overdistension of normal-appearing lung (classic pattern) and increased complexity of alveoli with increased radial alveolar counts (polyalveolar lobe or hyperplasia of lung; figure 13 shows the classic pattern and a polyalveolar lobe at the same power). These two morphological patterns may occur due to the different timing of an inciting lesion leading to anatomical or functional bronchial abnormality, and the degree of obstruction of the bronchus, with a relatively closed bronchus and fluid retention resulting in hyperplasia. Conversely, a weak bronchial wall without fluid retention would result in relatively normal lung development in utero, with the bronchus collapsing only after birth, leading to overdistension of alveoli [29].
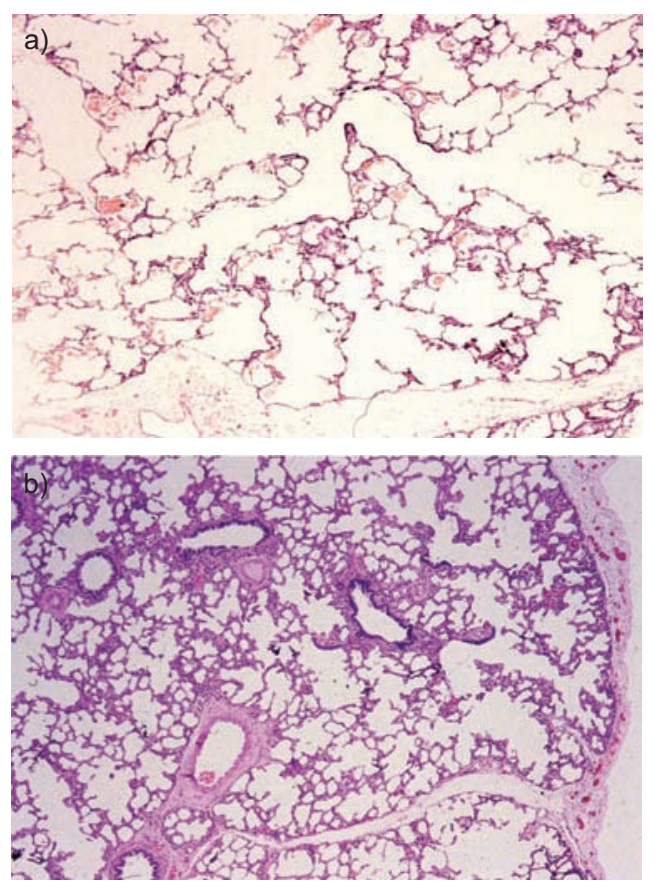

Fig. 13. - Infantile lobar emphysema. a) Classic pattern of overdistension of alveoli, and b) polyalveolar lobe with complex alveolar architecture but relatively normally sized alveoli (haematoxylin and eosin stain). 
Bronchogenic cyst. Bronchogenic cysts are thought to arise from abnormal budding of the ventral segment lung buds that give rise to the bronchial tree and lung. One hypothesis is that their position depends upon the timing of the developmental aberration that causes them. If it occurs early, then the cyst is located in the mediastinum (most commonly), but, if it occurs late, then the cyst is located within the lung tissue itself, most often in the lower lobes [30]. Another view is that case reports of intrapulmonary bronchogenic cysts probably represent instances of CPAM type 1 [23], although one series described 10 cases of pathologically verified intrapulmonary bronchogenic cyst [31].

\section{Summary}

A new and expanded classification of congenital pulmonary airway malformations (CPAM) of the lung identifies lesions on the basis of the likely site of origin and clinical and pathological features. Within the five types, recent reports have demonstrated an association of CPAM type 1 with bronchioloalveolar carcinoma (BAC), and a degree of confusion in separating CPAM type 4 from the purely cystic form of pleuropulmonary blastoma.

The CPAM type 1 lesion has been noted to contain clusters of mucogenic cells in $\sim 35 \%$ of cases, and these clusters are thought to predispose the patient to the development of BAC. The CPAM type 4 lesion, with its large and often thick-walled cysts lined with alveolar lining cells, may be confused with the cysts of type I pleuropulmonary blastoma, although its cyst walls contain subepithelial foci of rhabdomyosarcoma, almost exclusively underlying stretches of cuboidal-to-columnar epithelium, rather than the alveolar cell epithelium of CPAM type 4.

Other cystic or pseudocystic lung lesions include post-infarction peripheral cysts resulting from intrauterine pulmonary artery thrombosis. Similarly appearing cysts have been noted in Down's syndrome. Air-filled cysts within the interstitium are a feature of acute and persistent interstitial pulmonary emphysema, and are limited to the interlobular septa. Fluid-filled cysts of congenital pulmonary lymphangiectasia are present within the interlobular septa, and extend laterally from the septa beneath the pleura. Congenital pulmonary lymphangiectasia is also frequently associated with congenital malformations of the heart. Bronchogenic cysts are rarely seen in infants, and are solid lesions usually separate from the lung. Extralobar sequestrations are also nonaerated lesions separate from the lung and occasionally found within or beneath the diaphragm. Intralobar sequestrations are usually acquired lesions (through infection), and may display air- or fluid-filled cysts, representing re-epithelialised post-infectious abscesses. Finally, one of the most common pulmonary lesions in infants and children, infantile lobar emphysema, is not cystic but simply the overinflation of a segment of lung.

Keywords: Bronchioloalveolar carcinoma, bronchogenic cyst, congenital pulmonary airway malformation, extralobar sequestration, insterstitial pulmonary emphysema, pleuropulmonary blastoma. 


\section{References}

1. Ch'in KY, Tang MY. Congenital adenomatoid malformation of one lobe of a lung with general anasarca. Arch Path 1949; 48: 221-225.

2. Stocker JT, Madewell JE, Drake RM. Congenital cystic adenomatoid malformation of the lung. Classification and morphologic spectrum. Hum Pathol 1977; 8: 155-171.

3. Stocker JT. Congenital and developmental diseases. In: Dail DH, Hammer S, eds. Pulmonary Pathology. New York, Springer-Verlag, 1994; pp. 155-190.

4. Stocker JT. Congenital pulmonary airway malformation - a new name for and an expanded classification of congenital cystic adenomatoid malformation of the lung. Histopathology 2002; 41: Suppl. 2, 424-430.

5. Rutledge JC, Jensen P. Acinar dysplasia: a new form of pulmonary maldevelopment. Hum Pathol 1986; 17: 1290-1293.

6. Priest JR, McDermott MB, Bhatia S, Watterson J, Manivel JC, Dehner LP. Pleuropulmonary blastoma: a clinicopathologic study of 50 cases. Cancer 1997; 80: 147-161.

7. Gillespie LM, Fenton AC, Wright C. Acinar dysplasia: a rare cause of neonatal respiratory failure. Acta Paediatr 2004; 93: 712-713.

8. Davidson LA, Batman P, Fagan DG. Congenital acinar dysplasia: a rare cause of pulmonary hypoplasia. Histopathology 1998; 32: 57-59.

9. Stocker JT, Drake RM, Madewell JE. Cystic and congenital lung diseases in the newborn. Perspect Pediatr Pathol 1978; 4: 93-154.

10. Conran RM, Stocker JT. Extralobar sequestration with frequently associated congenital cystic adenomatoid malformation, type 2: report of 50 cases. Pediatr Dev Pathol 1999; 2: 454 463.

11. Okubo K, Mark EJ, Flieder D, et al. Bronchoalveolar carcinoma: clinical, radiologic, and pathologic factors and survival. J Thorac Cardiovasc Surg 1999; 118: 702-709.

12. Kantar M, Cetingul N, Veral A, Kansoy S, Ozcan C, Alper H. Rare tumors of the lung in children. Pediatr Hematol Oncol 2002; 19: 421-428.

13. Nanki N, Fujita J, Ohtsuki Y, et al. Occurrence of bronchioloalveolar cell carcinoma in two brothers: comparison of clinical features and immunohistochemical findings. Intern Med 2002; 41: 1002-1006.

14. Ioachimescu OC, Mehta AC. From cystic pulmonary airway malformation, to bronchioloalveolar carcinoma and adenocarcinoma of the lung. Eur Respir J 2005; 26: 1181-1187.

15. Benjamin DR, Cahill JL. Bronchioloalveolar carcinoma of the lung and congenital cystic adenomatoid malformation. Am J Clin Pathol 1991; 95: 889-892.

16. Ribet ME, Copin MC, Soots JG, Gosselin BH. Bronchioloalveolar carcinoma and congenital cystic adenomatoid malformation. Ann Thorac Surg 1995; 60: 1126-1128.

17. Ota H, Langston C, Honda T, Katsuyama T, Genta RM. Histochemical analysis of mucous cells of congenital adenomatoid malformation of the lung: insights into the carcinogenesis of pulmonary adenocarcinoma expressing gastric mucins. Am J Clin Pathol 1998; 110: 450-455.

18. Stacher E, Ullmann R, Halbwedl I, et al. Atypical goblet cell hyperplasia in congenital cystic adenomatoid malformation as a possible preneoplasia for pulmonary adenocarcinoma in childhood: a genetic analysis. Hum Pathol 2004; 35: 565-570.

19. Dehner L, Tazelaar H, Manabe T. Pleuropulmonary blastoma. In: TravisW, Brambilla E, MullerHermelink K, Harris CC, eds. World Health Classification of Tumours. Pathology and Genetics of Tumours of the Lung, Pleura, Thymus and Heart. Lyon, IARD Press, 2004; pp. 99-100.

20. Roque L, Rodrigues R, Martins C, et al. Comparative genomic hybridization analysis of a pleuropulmonary blastoma. Cancer Genet Cytogenet 2004; 149: 58-62.

21. Dehner L. Beware of "degenerating" congenital pulmonary cysts. Pediatr Surg Int 2005; 21: 123-124.

22. Stocker JT, McGill LC, Orsini EN. Post-infarction peripheral cysts of the lung in pediatric patients: a possible cause of idiopathic spontaneous pneumothorax. Pediatr Pulmonol 1985; 1: 7-18.

23. Stocker JT. The respiratory tract. In: Stocker JT, Dehner L, eds. Pediatric Pathology. Philadelphia, Lippincott Williams \& Wilkins, 2001; pp. 445-518. 
24. Stocker JT, Kagan-Hallet K. Extralobar pulmonary sequestration: analysis of 15 cases. Am J Clin Pathol 1979; 72: 917-925.

25. Stocker JT. Sequestrations of the lung. Semin Diagn Pathol 1986; 3: 106-121.

26. Stocker JT, Malczak HT. A study of pulmonary ligament arteries. Relationship to intralobar pulmonary sequestration. Chest 1984; 86: 611-615.

27. Chapdelaine J, Beaunoyer M, St-Vil D, et al. an underestimated presentation? J Pediatr Surg 2004; 39: 677-680.

28. Stocker JT, Madewell JE. Persistent interstitial pulmonary emphysema: another complication of the respiratory distress syndrome. Pediatrics 1977; 59: 847-857.

29. Mani H, Suarez E, Stocker JT. The morphologic spectrum of infantile lobar emphysema: a study of 33 cases. Paediatr Respir Rev 2004; 5: Suppl A, S313-S320.

30. Williams HJ, Johnson KJ. Imaging of congenital cystic lung lesions. Paediatr Respir Rev 2002; 3 : 120-127.

31. Tireli GA, Ozbey H, Temiz A, Salman T, Celik A. Bronchogenic cysts: a rare congenital cystic malformation of the lung. Surg Today 2004; 34: 573-576. 